\title{
Childhood-onset hypophosphatasia
}

INSERM

\section{Source}

INSERM. (1999). Orphanet: an online rare disease and orphan drug data base. Childhoodonset hypophosphatasia. ORPHA:247667

Childhood-onset hypophosphatasia is a rare, mildform of hypophosphatasia (see this term) characterized by onset after six months of age and widely variable clinical features from low bone mineral density for age, to unexplained fractures, skeletal deformities, and rickets with short stature and waddling gait. 